\title{
Evaluation of MirMe ${ }^{\circledR}$ Online Assessment for $21^{\text {st }}$ Century Skills:
}

\section{Situational Intelligence (SQ) and}

\section{Online psychometric assessment of $21^{\text {st }}$ century skills}

\author{
Shenghua Luan
}

Center for Adaptive Rationality, Max Planck Institute for Human Development

Mark R. Nowacki

School of Social Sciences, Singapore Management University

\section{Author Note}

ORCiD: Luan 0000-0001-9170-1416; Nowacki 0000-0002-1137-2489.

Luan is currently affiliated with Institute of Psychology, Chinese Academy of Sciences; Nowacki is now affiliated with LogicMills Learning Centre.

The authors gratefully acknowledge the institutional support of the Singapore Ministry of Education, Singapore Management University, and LogicMills, and the helpful assistance of Diogenes Nowacki and Lydia Khan.

Corresponding author: Mark Nowacki, mark@logicmills.com.

Declaration: Neither author was paid for this work. Nowacki was involved in the development of the assessment instrument discussed. 


\begin{abstract}
We here assess the Situational Intelligence (SQ) component of the MirMe assessment system for 21 st century skills. MirMe is an online, game-based psychometric instrument developed by LogicMills. The SQ component measures skills related to decision-making and critical thinking. It does so via AI driven heuristic engines that deploy analogs of "fast and frugal" heuristics. Approximately 7,000 participants (aged 5 to 92) and 25,000 gameplays were involved in the various validation studies. Results support the conclusion that MirMe's SQ measures are internally consistent (Cronbach alpha ranging from .71 to .93). Results also suggest that MirMe may be a better predictor of student academic performance (measured by GPA) than A-levels (MirMe $r^{2}=.265, p<.001$; A-levels $r^{2}=.209, p<.001$ ). MirMe also appears to predict the kinds of co-curricular activities students participate in both prior to and during university.
\end{abstract}




\section{Evaluation of MirMe ${ }^{\circledR}$ Online Assessment for $21^{\text {st }}$ Century Skills:}

\section{Situational Intelligence (SQ) and}

\section{Online psychometric assessment of $21^{\text {st }}$ century skills}

The development of $21^{\text {st }}$ century skills has been identified as a central concern by both ministries of education and employers. These are the skills sought for during college admissions and job interviews, and they significantly influence job fit and future career advancement. They are also instrumental to academic success. ${ }^{1}$ Consequently, the development of an objective, rigorous, accurate, and reliable means of assessing $21 \mathrm{st}$ century skills is greatly to be desired. This paper describes the validation process for the MirMe ${ }^{\circledR}$ Assessment System for $21^{\text {st }}$ Century Skills ("MirMe") created by LogicMills Learning Centre Pte Ltd. Among the $21^{\text {st }}$ century skills measured by MirMe is Situational Intelligence ("SQ"), which is assessed via the Decider module of the MirMe system. The Decider module within MirMe is the focus of the present study.

There are numerous competing popular schemata for categorizing and populating the list of $21^{\text {st }}$ century skills. ${ }^{2}$ In practice, mapping between the better-known schemata is fairly straightforward and which scheme one adopts is largely a matter of convenience. Inter-translation can often turn on a simple matter of nomenclature: critical thinking skills are sometimes called analytical thinking skills (as, e.g., in Singapore). ${ }^{3}$

The definition of $21^{\text {st }}$ century skills adopted for MirMe was constructed by surveying accounts of $21^{\text {st }}$ century skills articulated in multiple international educational jurisdictions, with particular attention being paid to Singapore, Australia, the UK, and the USA. Additionally, as these skills are often described as "employability skills," particular consideration was also devoted to published and first-hand accounts of $21^{\text {st }}$ century skills 
by employers. In the authors' experience, the framework articulated below captures between $90 \%$ to $95 \%$ of $21^{\text {st }}$ century skills described by various ministries and departments of education globally. ${ }^{4}$

The approach adopted for MirMe divides $21^{\text {st }}$ century skills into three major categories:

- Situational Intelligence (SQ) — the skills (and concepts) needed to make good decisions in a changing world;

- Collaborative Intelligence (CQ) - the skills (and concepts) needed to work with other people; and,

- Global Intelligence (GQ) - the skills (and concepts) and qualities needed to be an effective global citizen.

A graphical representation of the relations among these three components is given in Figure 1 below. SQ and CQ may be considered as pillar skills supporting GQ. That is, GQ takes up and integrates the lower pillar skills upon which it rests, resulting in new skills. A useful comparison is the relationship between skill in negotiation (a high-level, integrated skill akin to GQ) and its pillar skills (akin to SQ and CQ). Skill in negotiation depends upon but is not reducible to its various pillar skills, which include communication skills, skills for setting and prioritising goals, skill in cost/benefit analysis, and so on. 
Figure 1. Framework for $21^{\text {st }}$ century skills adopted for MirMe.

\section{Validation overview}

The SQ measures assessed by the Decider module were carefully developed, reflecting insights gathered from more than eight years of observation of how participants played and described their own playing of a game similar to the Decider, and how that base game functioned as an assessment tool in concrete teaching practice. Based on the experience of teaching and assessing $21^{\text {st }}$ century skills for over 80,000 Singapore students of various ages, the selected measures all had high face validity. At the time, the Decider had more than 25,000 gameplays and 7,000 users as part of its various validation studies. Some of these studies, especially those involving industry partners, are subject to confidentiality agreements. What follows are studies approved for external publication.

The Decider assessment module consists of an abstract strategy game that is played three times as well as a brief 15 yes/no question survey. Upon completion of the assessment, the Decider calculates an overall summative or holistic score for SQ. This summative score is calculated from three major components (called "SQ Categories"), each of which in turn is calculated from multiple sub-components (each of which again depends on multiple sub-sub-measures). See Figure 2 below.

Figure 2. Component measures of the Decider SQ assessment.

As may be seen from Figure 2, the Decider is designed to measure SQ, understood as the skills we need to make good decisions in a changing world. The Decider's overall $S Q$-Score represents a holistic measure of this.

The SQ-Score is, in turn, built upon three components. In general, a person 
possessing situational intelligence displays three characteristics: First, you must be able to Jump in and know where you are ("J-Score"). That is, one must be able to size up an environment and quickly identify significant patterns and key drivers in that environment. Second, you should Know what you can do ("K-Score"). That is, one should be able to identify options and think ahead. Third, you must be able to Do it and see if it works ("D-Score"). This means that one is able to assimilate feedback from the environment and adapt to that feedback in a flexible manner. The overall SQ-score is determined by the participant's J-Score, K-Score, and D-Score.

As is usual in the development of a novel psychometric instrument, considerable refinement from a more complex initial form was required. In the present case, a total of 17 component measures were originally proposed, only 13 of which were retained. Again, the initial reflected insights gathered from more than eight years of observation of how students played the game and how the game activity functioned as an assessment tool in concrete teaching practice. Based on our experience, the selected measures all had high face validity.

\section{Study \#1}

To understand the psychometric properties of the 17 original Decider measures, we began with a principal component analysis ("PCA"). We administered the Decider assessment to two different samples: the first a secondary school, which involved 379 participants (ages 13 to 14); the second a university, which involved 352 participants. Genders were evenly represented in both cases. Our goal was two-fold: (a) to examine the different components assessed by the measures, and (b) to identify potentially problematic measures for further consideration and improvement. The results of this 
analysis can be found in Table 1 .

Table 1. PCA results for the Decider SQ assessment.

Among the 17 initial measures, PCA results lead to 13 measures pertaining to four components being selected for both samples. The percent of variance explained by those items was $83 \%$ for the Secondary School sample and $85 \%$ for the University sample. The 13 measures finally selected (see Fig. 2 above) were used to build our final three SQ components of Jump in and know where you are, Know what you can do, and Do it and see if it works.

Consistent with what we had conceptualized in the design stage, there appeared to be four meta-measures that summarized what is being captured by the individual measures. The measures loaded in each component also overlap greatly with our conceptualizations. The largest difference between theory and data, however, is that three measures did not enter into any of the four components. Upon close inspection we found that one was correlated too highly with one of the 13 included measures; the second simply had low loadings across board; and the third did not produce enough variation among the subjects. And, to anticipate somewhat, we ultimately decided to remove the fourth meta-measure.

Among the 17 initial measures, PCA results lead to 13 measures pertaining to four components being selected for both samples. The percent of variance explained by those items was $83 \%$ for the Secondary School sample and $85 \%$ for the University sample. The 13 measures finally selected (see Figure 2 above) were used to build our final three SQ components of Jump in and know where you are, Know what you can do, and Do it and see if it works. 
Consistent with what we had conceptualized in the design stage, there appeared to be four meta-measures that summarized what is being captured by the individual measures. The measures loaded in each component also overlap greatly with our conceptualizations. The major difference between theory and data, however, was that three of the measures did not enter into any of the four components. Upon close inspection we found that one was correlated too highly with one of the 13 included measures; the second simply had low loadings across board; and the third did not produce enough variation among the subjects. To anticipate somewhat, we ultimately decided to remove the fourth meta-measure.

With the four meta-components and the measures in each determined, we calculated the Cronbach alphas for all components in each sample. (See Table 2.) In general, the numbers are quite high and within an acceptable range, thus supporting the internal consistency of the assessment. ${ }^{5}$ Moreover, while it would be reasonable to claim that Component 3 (in Table 2) is acceptable with respect to internal consistency, upon further reflection the decision was made to excise it from the final version of the Decider.

Table 2. Internal consistency of Decider components (Cronbach alpha).

To see how the Decider correlates with other academic assessments and aptitude tests, we also collected four different measures on the two participant samples. These are summarised in Table 3 below.

Table 3. Decider correlations with other measures for sample groups. 
We begin our consideration with the secondary school sample. For this group, we asked that students complete at least 5 trials of the game. Unsurprisingly, not all students complied, so the final effective sample size is only a subset of all students. The validation measure we collected for the secondary students was their PSLE score, taken at the end of the academic year immediately prior to entry into secondary school. ${ }^{6}$

For the university sample, there are two sub-samples, each of which includes students from all years and from diverse majors in the university. The first university sub-sample consists of a generic university-wide pool of students who were taking different courses at the time. There are two validation measures for this sample: the students' current GPA (i.e., grade point average, measured on a 4-point scale) and their A-level scores (taken before entering university). The second university sub-sample consists of students currently taking the Analytical Skills course ("AS-course"), a course in critical thinking required for all students at the university. The AS-course is typically taken during the first year of university (92 participants, or $86 \%$ of the sub-sample), but due to scheduling factors students from all four years are represented (the remaining 15 participants, or $14 \%$ of the sub-sample). There is one validation measure for this sample: the student's final grade in the AS-course. We asked all students to complete at least 3 trials of the game; however, not all complied, which resulted in a reduced effective sample size.

We used mainly regression analysis to analyse the predictive validity of MirMe Decider measures. In each sample or subsample, we first conducted a Generalized Linear Model ("GLM") analysis. The goal was to select the best model, measured by Bayesian Information Criterion ("BIC"), based on the different measures of the Decider. We then calculated the adjusted $r^{2}$ value of this model. The results are shown in the last column of 
the table. As is usually the case with psychometric instruments, the Decider could possibly achieve different levels of predictive validity depending on the sample and validation measure. The results suggest that the Decider tracks student academic performance, with a slightly greater explanatory power for university-age students than secondary school students.

\section{Study \#2}

We then wished to consider how MirMe performed relative to other intuitively important measures within student life. The Decider was administered to 128 university students, 45 male and 83 female. Data collected included A-level results, academic GPA to-date, and the co-curricular activities ("CCAs") both prior to and subsequent to entering university. The understanding of what constitutes a CCA was broad, including clubs, charitable organisations, professional organisations, and in general any student-centric, organised activity that falls outside the standard academic courses. The CCAs were coded along two dimensions: (1) group versus individual, and (2) cognitive versus non- cognitive. Thus, chess club was coded as (individual + cognitive), whereas dragon boating was coded as (group + non-cognitive). The results are given in Table 4 .

Table 4. MirMe correlated with A-level, GPA, and CCA for university students.

The results suggest that the Decider may be a more accurate predictor of university academic performance (as measured by GPA) than A-level results. Inspection of Table 4 further reveals that the Decider, when taken in conjunction with A-level results, yields a better predictor of student GPA than either measure taken individually. 
This is consistent with the hypothesis that whereas MirMe focuses upon the assessment of skills, the A-levels place greater emphasis upon content knowledge, both of which are important contributors to GPA.

Furthermore, according to this study, the Decider is also capable of predicting, both retrospectively and prospectively, the CCAs that participants engage in. We believe that this may be of interest to university administrators who wish to encourage and support diversity in student interests and thereby enhance the students' educational experience. It is further hypothesized that such information may be relevant for highly- desirable academic and business outcomes such as team optimisation.

\section{Discussion}

The research results support the claim that MirMe is an effective assessment for Situational Intelligence. As a psychometric tool, MirMe has a number of advantages. First, it is currently the only comprehensive testing instrument for $21^{\text {st }}$ century skills. ${ }^{7}$ Second, the MirMe SQ assessment is impossible to game, precisely because it uses a game. For survey-based instruments, such as those found in corporate environments, familiarity with the instrument may allow participants to pre-determine their desired outcomes. However, it is impossible to memorize a good way through the Decider, in much the same way that it is impossible to memorize all the best moves in chess. Third, the Decider is quick to administer: participants can navigate the assessment in under 45 minutes. Fourth, because the Decider is based on a game, it is non-threatening and likely to elicit a meaningful and engaged response.

While the results obtained thus far are positive and suggestive, we opine that 
future research should focus on the Decider's performance relative to the SAT (“Scholastic Aptitude Test”), which is widely used by North American universities. As a preliminary consideration, we note that published studies of the SAT typically report that the percent of variance in first- year GPA predicted for by the SAT (Reading + Mathematics) score is between 13\% and 20\%. Using the College Board's own study of the latest version of their test (Westrick et al., 2019), the correlation between SAT and first year GPA has adjusted $r=.51$, entailing a percent variance of $26 \%$ (i.e., adjusted $r^{2}=$ .26). In line with the results of Study \#2, the Decider is predicted to perform as well or better than the SAT, for the Decider accounts for $26.5 \%$ (adjusted $r^{2}=.265$ ). Furthermore, as appears to be the case with the A-levels, we hypothesize that the explanatory power of the Decider plus the SAT will be greater than either measure alone. 


\section{Endnotes}

1. A suggestive case is documented in the Singapore Ministry of Education Report (2010). This report describes the validation process for the LogicMills ATS ${ }^{\circledR}$ curriculum involving more than 2,000 students over two years. The LogicMills curricula, delivered in less than 30 hours over a single academic year, was shown to boost scores on high-stakes exams by $16.8 \%$ or more $\left(p<.000, r^{2} \approx .85\right)$. Students who represent Singapore on the PISA exam (administered by the OECD) typically go through either the LogicMills program or a white-labelled version of it. The influence of LogicMills is perhaps best seen in Singapore's performance on the special tests of the PISA. In 2012, Singapore students came $1^{\text {st }}$ for problem solving skills; in $2015,1^{\text {st }}$ for collaborative problem solving; and in 2018, $1^{\text {st }}$ in global competencies.

2. Examples of well-known schemes, all of which are accessible online, include: Partnership for $21^{\text {st }}$ Century Learning "P21"; UNESCO International Bureau of Education "21st century skills"; ACARA “General Capabilities"; Singapore Ministry of Education " $21^{\text {st }}$ Century Competencies"; and Assessment \& Teaching of $21^{\text {st }}$ Century Skills Research Group "ATC21”. For discussion of some of the issues that arise from having diverse accounts of $21^{\text {st }}$ century skills see Joynes, Rossignoli \& Amonoo-Kuofi (2019).

3. This is, perhaps, due to cultural norms; in Asia direct conflict is usually avoided and it is considered impolite to criticize. With respect to content, though, the terms are identical.

4. The lion's share of the missing $5-10 \%$ is typically due to inclusion of country-specific factual knowledge. Singapore, for instance, includes knowledge of its history and political institutions within $21^{\text {st }}$ century skills. Other mapping challenges arise due to 
diverse notions of digital literacy, which in some cases can be highly specific: e.g., coding is sometimes considered essential, sometimes not; fluency in using specific search engines is sometimes required, other times not.

5. Typically, a Cronbach alpha of .70 or higher is considered acceptable in social science research. There are, however, many cases where lower Cronbach alphas are deemed appropriate, as argued in Taber (2017).

6. The PSLE, or "Primary School Leaving Examination," is a mandatory national examination that all students in Singapore take at the end of Primary 6. English, Mathematics, Science, and Mother Tongue are assessed, with approximately 2 hours dedicated to each subject. The PSLE determines whether a Singapore student is permitted to move on to secondary school, determines which secondary school the student may enter, and determines the academic stream within which the student is placed. To a significant degree, who gets to attend university is determined for Singaporeans at the age 12 .

7. The MirMe assessment has been used in highly diverse contexts. See: Seow, Pan \& Koh (2018), and Yong \& Shin (2015). Another (2021) study involving 109 working adults was undertaken for the Singapore Ministry of Manpower. 


\section{References}

ACARA “General Capabilities”. Retrieved 31 August 2021 from

https://www.australiancurriculum.edu.au/f-10-curriculum/general- capabilities/

Assessment and Teaching of $21^{\text {st }}$ Century Skills Research Group "ATC21". Retrieved 31

August 2021 from http://www.atc21s.org/

Joynes, C., Rossignoli, S., \& Fenyiwa Amonoo-Kuofi, E. (2019). 21st Century Skills:

Evidence of issues in definition, demand and delivery for development contexts (K4D

Report). Brighton: Institute of Development Studies. Retrieved 31 August 2021 from https://assets.publishing.service.gov.uk/media/5d71187ce5274a097c07b985/21st cent ury.pdf

Partnership for $21^{\text {st }}$ Century Learning "P21". Retrieved 31 August 2021, from https://www.battelleforkids.org/networks/p21

Seow, P., Pan, G., \& Koh, G. (2019). Examining an experiential learning approach to prepare students for the volatile, uncertain, complex and ambiguous (VUCA) work environment. The International Journal of Management Education, 17(1), 62-76. doi:10.1016/j.ijme.2018.12.001

Singapore Ministry of Education Report (2010). Explicit Teaching of analytical thinking skills (ATS) through games-based facilitation for all courses (in Primary and Secondary schools) for Higher academic achievement. MOE Innovation Fund, 2008-2010, \$1.09m grant research project. 
Singapore Ministry of Education " $21^{\text {st }}$ Century Competencies”. Retrieved 31 August 2021 from https://www.moe.gov.sg/education-in-sg/21st- century-competencies

Taber, K. S. (2017). The Use of Cronbach's Alpha When Developing and Reporting Research Instruments in Science Education. Research in Science Education, 48(6), 1273-1296.

UNESCO International Bureau of Education " $21^{\text {st }}$ century skills". Retrieved 31 August 2021 from http://www.ibe.unesco.org/en/glossary-curriculum-terminology/t/twenty-first-century-s $\underline{\text { kills }}$

Westrick, P. A., Marini, J. P., Young, L., Ng, H., Shmueli, D., \& Shaw, E. J. (2019, May). Validity of the SAT ${ }^{\circledR}$ for Predicting First-Year Grades and Retention to the Second Year (Rep.). Retrieved July 14, 2020, from CollegeBoard website: https://collegereadiness.collegeboard.org/pdf/national-sat-validity-study.pdf

Yong, M., \& Shin, Y. (2015). Psychometric Assessment of 21st Century Employability Skills: Situational Intelligence and Social Factors. Humanities and Social Sciences Research Programme (HSSRP), 189-196. 


\section{Tables and Figures}

Figure 1. Framework for $21^{\text {st }}$ century skills adopted for MirMe.

\section{GQ: Values + Talent + Lead/Follow}

1. Know your own values

2. Thereafter, you can be open to others from all walks of life

3. This openness takes the form of drawing upon your own talents and talents of others, sometimes leading and sometimes following,

to get things done

4. When you are comfortable doing all this, you are a global citizen
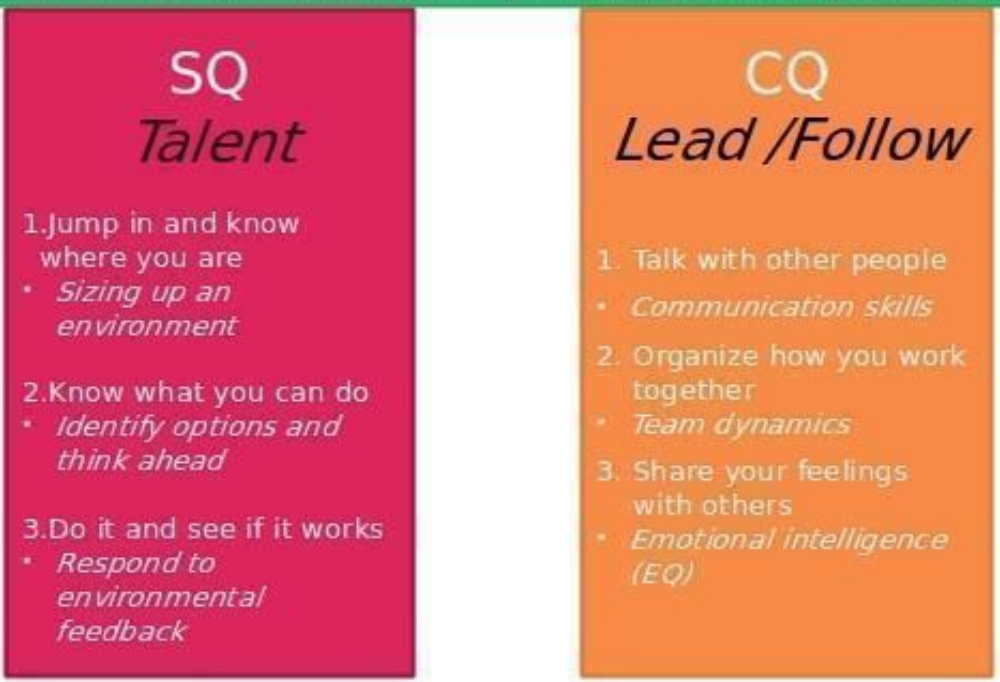
Figure 2. Component measures of the Decider SQ assessment.

\begin{tabular}{|c|c|}
\hline \multicolumn{2}{|c|}{ SQ: the skills we need to make good decisions in a changing world } \\
\hline SQ Category & Components \\
\hline $\begin{array}{l}\text { 1. Jump in and know where } \\
\text { you are } \\
\text { - Size up an environment } \\
\text { - J - Score }\end{array}$ & $\begin{array}{l}\text { 1. Identify and set goals } \\
\text { 2. Prioritize needs } \\
\text { 3. Evaluate options } \\
\text { 4. Pursue multiple goals } \\
\text { 5. Utilize resources efficiently } \\
\text { 6. Select appropriate solutions among alternatives }\end{array}$ \\
\hline $\begin{array}{l}\text { 7. Know what you can do } \\
\text { - Identify options and plan } \\
\text { ahead } \\
\text { - K - Score }\end{array}$ & $\begin{array}{l}\text { 1. Create opportunities } \\
\text { 2. Make accurate predictions/forecasts } \\
\text { 3. Create first-mover advantage / Carve out a niche } \\
\text { 4. Tackle problems before they arise }\end{array}$ \\
\hline $\begin{array}{l}\text { 5. Do it and see if it works } \\
\text { - Respond to feedback } \\
\text { - } \text { D - Score }\end{array}$ & $\begin{array}{l}\text { 1. Modify behavior during competition } \\
\text { 2. Prevent / block competition } \\
\text { 3. Find new resources }\end{array}$ \\
\hline
\end{tabular}


Table 1. PCA results for the Decider SQ assessment.

\begin{tabular}{|c|c|c|c|c|c|}
\hline Sample & Measure & Component 1 & Component 2 & Component 3 & Component 4 \\
\hline \multirow{13}{*}{$\begin{array}{l}\text { Secondary } \\
\text { School }\end{array}$} & Measure 1 & 0.94 & 0.28 & 0.03 & -0.10 \\
\hline & Measure 2 & 0.91 & 0.21 & 0.06 & 0.29 \\
\hline & Measure 3 & 0.89 & 0.44 & 0.04 & -0.05 \\
\hline & Measure 4 & 0.82 & 0.11 & 0.50 & -0.09 \\
\hline & Measure 5 & 0.20 & 0.89 & 0.11 & -0.01 \\
\hline & Measure 6 & 0.14 & 0.92 & 0.16 & -0.02 \\
\hline & Measure 7 & 0.59 & 0.77 & 0.08 & -0.01 \\
\hline & Measure 8 & 0.40 & 0.60 & 0.08 & 0.16 \\
\hline & Measure 9 & 0.01 & 0.36 & 0.91 & -0.01 \\
\hline & Measure 10 & -0.08 & 0.17 & 0.87 & 0.40 \\
\hline & Measure 11 & 0.34 & -0.22 & 0.73 & -0.07 \\
\hline & Measure 12 & -0.11 & -0.19 & 0.08 & 0.95 \\
\hline & Measure 13 & 0.28 & 0.46 & 0.11 & 0.77 \\
\hline \multirow{13}{*}{ University } & Measure 1 & 0.98 & 0.22 & 0.19 & -0.11 \\
\hline & Measure 2 & 0.89 & 0.28 & -0.02 & 0.10 \\
\hline & Measure 3 & 0.72 & 0.42 & 0.11 & -0.09 \\
\hline & Measure 4 & 0.71 & 0.20 & 0.58 & -0.27 \\
\hline & Measure 5 & 0.20 & 0.81 & 0.09 & 0.07 \\
\hline & Measure 6 & 0.20 & 0.78 & 0.18 & -0.11 \\
\hline & Measure 7 & 0.70 & 0.63 & -0.04 & 0.00 \\
\hline & Measure 8 & 0.55 & 0.65 & -0.03 & 0.11 \\
\hline & Measure 9 & 0.02 & 0.34 & 0.92 & 0.02 \\
\hline & Measure 10 & -0.23 & 0.15 & 0.94 & 0.34 \\
\hline & Measure 11 & 0.27 & -0.08 & 0.78 & -0.02 \\
\hline & Measure 12 & -0.22 & -0.16 & 0.01 & 0.78 \\
\hline & Measure 13 & 0.52 & 0.58 & 0.13 & 0.94 \\
\hline
\end{tabular}


Table 2. Internal consistency of Decider components (Cronbach $\boldsymbol{\alpha}$ ).

\begin{tabular}{|c|c|c|}
\hline \multicolumn{3}{|c|}{ Cronbach $\boldsymbol{\alpha}$ for each game measure component } \\
\hline & Secondary School & University \\
\hline Component 1 & 0.93 & 0.93 \\
\hline Component 2 & 0.90 & 0.88 \\
\hline Component 3 & 0.67 & 0.72 \\
\hline Component 4 & 0.71 & 0.82 \\
\hline
\end{tabular}


Table 3. Decider correlations with other measures for sample groups.

\begin{tabular}{|c|c|c|c|}
\hline Sample & $\begin{array}{c}\text { Effective } \\
\text { Sample } \\
\text { Size }\end{array}$ & $\begin{array}{c}\text { Validation } \\
\text { Measure }\end{array}$ & $\begin{array}{c}\text { Achieved R }{ }^{2} \\
\text { Using MirMe } \\
\text { Measures }\end{array}$ \\
\hline Secondary School & 248 & PSLE score & 0.184 \\
\hline $\begin{array}{c}\text { University } \\
\text { wide }\end{array}$ & 68 & Current GPA & 0.335 \\
\hline $\begin{array}{c}\text { Analytical } \\
\text { Skills } \\
\text { classes }\end{array}$ & 107 & Final grade & 0.128 \\
\hline
\end{tabular}


Table 4. MirMe correlated with A-level, GPA, and CCA for university students.

\begin{tabular}{l|l|l}
$\begin{array}{l}\text { Measure } \\
\text { MirMe }\end{array}$ & $\begin{array}{l}\mathbf{R}^{2} / \text { Adiusted } \mathbf{R}^{2}, \\
\boldsymbol{p} \text { value }\end{array}$ \\
\hline MirMe & GPA & $\underline{\mathrm{R}}^{2}=.211, p<.001$ \\
\hline A-levels & GPA & $\underline{\mathrm{R}}^{2}=.265, p<.001$ \\
\hline MirMe +A-levels & GPA & $\underline{\mathrm{R}}^{2}=.209, p<.001$ \\
\hline MirMe & Pre-U CCA - cognitive & $\mathrm{R}^{2}=.361, p<.001$ \\
\hline MirMe & Uni-CCA - cognitive & $\mathrm{R}^{2}=.238, p<.001$ \\
\hline MirMe & Pre-U CCA-group & $\mathrm{R}^{2}=.178, p<.01$ \\
\hline MirMe & Uni-CCA-group & $\mathrm{R}^{2}=.182, p=.039$
\end{tabular}

